\title{
Probiotic Lactobacillus species Inhibitory Effect on The Growth of Oral Streptococci
}

\author{
Wah Wah Than', Saw Sandar Maw ${ }^{2}$, Zaw Khaing Oo ${ }^{3}$ and Reemon Htun ${ }^{4}$ \\ Research Scholar ${ }^{1}$ and Professor ${ }^{2,3,4}$ \\ ${ }^{1-4}$ Department of Biotechnology, Mandalay 05072 \\ Mandalay Technological University \\ Mandalay, Mandalay State
}

Myanmar

\begin{abstract}
Oral and dental infections are among the most prevalent infections of man. All people suffer from dental caries at some phase of their life span. The mouth is indeed an important source of infections and poor oral health affects a variety of systemic diseases. The aim of this research is to isolate, identify acid-producing lactic acid bacteria (LAB) from fermented fruits juice and followed by the 16S rRNA gene sequences of the isolated bacterial strains Lactobacillus Plantarum S1, Leuconostoc mesenteroides (SC and $P P)$ and Burkholderia cenocepia NP were compared with reference strain sequences. Oral Streptococci were important in the etiology of dental caries. We targeted for isolation and biochemical identification of oral bacteria (isolates grown in SMAB agar) and screened antibacterial activity (agar well diffusion assay) of Lactobacillus species against oral Streptococci. Two Lactobacillus isolates (S1 and PP) were observed to behave a good antagonistic activity against oral Streptococcus strain with differences in the size of inhibition zone $(\mathrm{mm})$. The zone diameter of NP broth against Streptococcus sp. was $10 \mathrm{~mm}$. Oral Streptococci was not inhibited by SC broth. In this study, Leuconostoc mesenteroides (PP) showed the highest inhibition zone (13 mm) against oral Streptococci.
\end{abstract}

Key Words: Lactic Acid Bacteria, Antibacterial Activity, Dental Caries, Oral Streptococci, Biochemical Identification.

\section{INTRODUCTION}

Lactic acid bacteria (LAB) are fermentative microorganisms which are capable of growth over a wide pH range in the presence of organic acids. Application of LAB is as source of probiotics, starter cultures, antimicrobial agents, vitamins, enzymes increase consumer's demands for natural products and functional foods in relation with human health. World Health Organization (WHO) defined probiotic bacteria as "live microorganism which when administered in adequate amounts confer a health benefit on the host”. Commercial probiotic are mainly genus Lactobacillus with over one hundred species, such as Lactobacillus acidophilus, L. casei, L. rhamnosus, L. plantarum, L. bulgaricus etc. [1]

In 2002 the World Health Organization defined the concept of probiotics as follows: "A supplement of living microorganisms that bring a health benefit by improving the balance of the intestinal microbiota" [2]. Probiotic effect may include sites such as the oral cavity, the intestine, the vagina, and the skin [3]. Probiotics are given as functional foods or dietary supplements, and function activating the mucosal immune system, preventing pathogen colonization and translocation by strengthening the mucosal barrier, interfering with pathogen colonization and, in some instances, by producing secretory antibacterial substances [4].

Most probiotics are Gram-positive bacteria that belong to the genera Lactobacillus and Bifidobacterium [5]. Lactobacilli make approximately $1 \%$ of the cultivable oral microbiota [6]. Bacterial strains investigated in the oral health perspective for their probiotic effect. The genera Lactobacillus include L. bulgaricus, L. rhamnosus, L. casei, L. dellbrueckii subsp. Bulgaricus, L. casei strain Shirota, L. paracasei, L. johnsonii, L. reuteri, L. acidophilus, L. plantarum, L. helveticus L. fermentum, Lactococcus, Lactococcus lactis. The genera Bifidobacterium include B. breve, B. lactis, B. longum, B. adolescentis, B. infantis, Weissella, W. cibaria, Propionibacterium, P. freudenreichii subsp. Shermanii, Streptococcus, S. salivarius, S. thermophiles, S. sanguinis [7].

When dental plaque microorganisms ferment sugar into organic acids which then lower the oral fluid pH [8]. Microorganisms are found free in saliva, covering mucosal surfaces, and organized in supra- and sub-gingival dental plaque. In plaque the 
microorganisms form highly structured biofilms where bacteria appear to communicate with each other [9]. $1 \mathrm{mg}$ of plaque may contain up to $10^{11}$ bacteria. The viridans group Streptococci constitute the majority of the indigenous oral microbiota, but practically all human pathogenic bacteria known occasionally may also harbor in the mouth. More than 700 microbial species have been identified in the mouth and it is estimated that each individual may carry 200-300 species at the same time [10].

Functioning defensive mechanisms of the oral cavity usually maintain homeostasis and prevent overgrowth of micro-organisms. If the balance is disturbed for one reason or another, the result may be colonization and emergence of potentially pathogenic microbiota which detrimentally affects not only the oral and dental health but also has systemic health consequences [11]. Therefore, the objective of this research has been focused on the isolation and identification of probiotic Lactobacillus and screen them for antibacterial activity against oral Streptococcus species.

\section{MATERIALS AND METHODS}

\subsection{Sample Collection}

All samples (rotten fruits of papaya and strawberry, palm fruit pulp and sugar cane juice) were collected from local markets in Mandalay during summer. Approximately $20 \mathrm{~g}$ of fruits were cut and incubated in $100 \mathrm{ml}$ of enrichment medium (normal saline containing $4 \mathrm{ml}$ of $96 \%$ ethanol) at $37^{\circ} \mathrm{C}$ for 7 days. Then $100 \mathrm{ml}$ of sugar cane juice in glucose ethanol yeast extract broth were incubated at $37^{\circ} \mathrm{C}$ for 7 days.

\subsection{Isolation of Lactic Acid Producing Bacteria}

After seven days incubation, three fruits juice and sugar cane juice started alcoholic fermentation, followed by an evident change to the acid fermentation process. One milliliter from each solution was used as inoculum presenting lactic acid producing bacteria, was added to plates containing standard glucose yeast extract supplemented with calcium carbonate (GYC) medium and all plates were incubated at $30^{\circ} \mathrm{C}$ for 3-5 days. Lactic acid producing bacteria were identified as transparent halo appearance around colonies. Colonies presenting a transparent halo were transferred again to sterile Man-Rogosa-Sharpe (MRS) agar plates. The petri dishes were incubated at $37^{\circ} \mathrm{C}$ for 24 hours. Morphological examination of culture isolate was made by Gram's staining method. All slides were examined with an optical microscope and selected colonies were tested for catalase production. The isolated strains were kept in $12 \%$ (w/v) sterile skim milk and $25 \%$ (w/v) glycerol then stored at $-20^{\circ} \mathrm{C}$ in deep freezer.

\subsection{DNA Extraction and PCR Identification of Lactic Acid Producing Bacteria}

Isolated four bacterial strains from strawberry $\left(\mathrm{S}_{1}\right)$, sugar cane juice (SC), palm fruit pulp (PP) and papaya (NP) were identified by sequencing. In this analysis, PCR products of $16 \mathrm{~S}$ rRNA sequences of four bacterial strains were aligned with the reference strain sequences in the NCBI GenBank by using Basic Local Alignment Search Tool (BLAST).

\subsection{Isolation and Morphological Identification of Streptococcus species}

Samples were taken from teeth decay and whole mouth plaque samples by swabbing all smooth surfaces of the teeth. To provide homogeneous suspensions of plaque bacteria, plaque samples with normal saline were vortexed. Dilution of plaque samples were smeared onto selective Mitis-Salivarius- Bacitracin agar (MSB) plates for isolating of morphological differentiation. And then secondary agar, Strep Mannitol Agar with Bacitracin (SMAB) was used for confirmation of Streptococcus species. SMAB contained mannitol $(15 \mathrm{~g} / \mathrm{L})$, proteose peptone $(20 \mathrm{~g} / \mathrm{L})$, yeast extract $(5 \mathrm{~g} / \mathrm{L}), \mathrm{NaCl}(5 \mathrm{~g} / \mathrm{L}), \mathrm{K}_{2} \mathrm{HPO}_{4}(1 \mathrm{~g} / \mathrm{L})$, bromocresol purple (32 mg/L), agar (15 g/L), and bacitracin (150U added after autoclaving). The $\mathrm{pH}$ was adjusted to 7.6 before autoclaving. Isolated MSB colonies were streaked on the surface of standard medium SMAB plates for further identification. Plates were incubated at $37^{\circ} \mathrm{C}$ for 24 hours.

Two isolated bacteria were prepared with Gram stain to identify after inoculated in culture. All colony morphological arrangement were studied by using microscope. Selected colonies were tested for catalase production compared with Staphylococcus species. Fresh liquid cultures of isolates were used for catalase test by dropping 3\% hydrogen peroxide solution onto $1 \mathrm{ml}$ of overnight cultures.

\subsection{Agar Well Diffusion Assay for Antimicrobial Screening of Lactobacillus species}

The antimicrobial activity of Lactobacillus species on Streptococcus was performed by agar well diffusion assay [12]. Four Lactobacillus species $\left(\mathrm{S}_{1}, \mathrm{SC}, \mathrm{PP}\right.$ and NP) were incubated in MRS broth at $37^{\circ} \mathrm{C}$ for 24 hours. Streptococcus bacteria was incubated in Muller Hinton Broth at $37^{\circ} \mathrm{C}$ for 24 hours. The broth culture of Streptococcus strains were prepared by spreading 0.1 $\mathrm{ml}$ of inoculum onto Muller Hinton agar plates. Each well of diameter $9 \mathrm{~mm}$ were made in each of the plates using sterilized well cutter. To each well, aliquots of $50 \mu 1$ culture broth $\left(\mathrm{S}_{1}, \mathrm{SC}, \mathrm{PP}\right.$ and NP) were filled to the well with the help of micropipette. One well with positive control $(\mathrm{C}+) 25 \mu \mathrm{g} / \mathrm{ml}$ antibiotic (Ampicillin) and the other kept as negative control (C-) only MRS broth. 
Plates were incubated at $37^{\circ} \mathrm{C}$ for 24 hour to check growth of oral pathogen. After incubation, inhibition zones around the wells were measured and recorded in millimeter.

\section{RESULTS AND DISCUSSION}

In this research, isolation, identification and purification of acid producing bacteria were conducted. For isolation of indigenous acid producing bacteria, various sources such as papaya, strawberry, palm fruit pulp and sugar cane juice were used for industrial uses as starter microorganisms. Four isolates from selected samples $\left(\mathrm{S}_{1}, \mathrm{SC}, \mathrm{PP}\right.$ and $\mathrm{NP}$ ) were seen the biggest clear zone around the colonies on standard medium (GYC). This indicated acid production capability of acid producing bacteria.

\subsection{PCR Identification of Lactic Acid Producing Bacteria}

In analysis of isolated four bacterial strains, the $16 \mathrm{~S}$ rRNA gene sequences of the isolated bacterial strains $\left(\mathrm{S}_{1}, \mathrm{PP}, \mathrm{NP}\right.$ and $\left.\mathrm{SC}\right)$ were compared with reference strain sequences deposited in the National Center for Biotechnology Information (NCBI) GenBank public database.

Table1. Isolated strains and its consistency

\begin{tabular}{|c|c|c|}
\hline Strain Number & Most Similar Strain & Consistency \\
\hline $\mathrm{S}_{1}$ & Lactobacillus plantarum & $98 \%$ \\
\hline $\mathrm{PP}$ & Leuconostoc mesenteroides & $96 \%$ \\
\hline $\mathrm{NP}$ & Burkholderia cenocepacia & $99 \%$ \\
\hline $\mathrm{SC}$ & Leuconostoc mesenteroides & $91 \%$ \\
\hline
\end{tabular}

\subsection{Characterization of Oral Streptococcus Bacteria}

The morphological characteristics of isolated oral bacteria were shown in Figure1. Two isolated oral bacteria (S3/1 and S3/2) were observed, belong to Gram positive, coccus or spherical in shape and formed pairs or chains in arrangement.

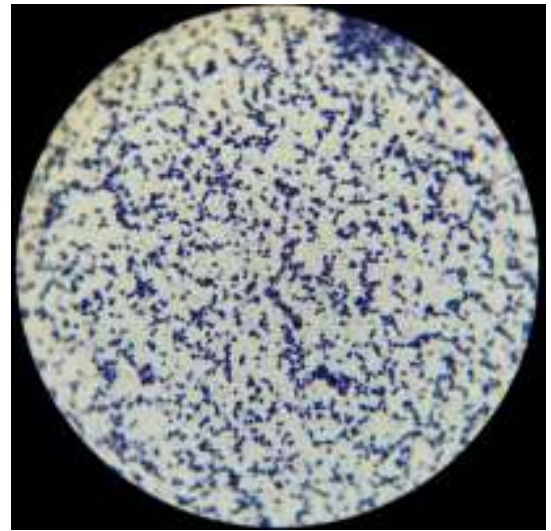

$\mathrm{S} 3 / 1$

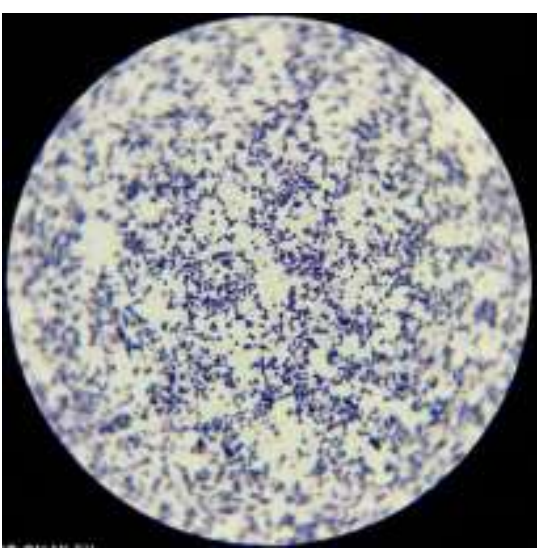

$\mathrm{S} 3 / 2$

Figure1. Microscopic Morphology of Isolated Oral Streptococcus Bacteria

\subsection{Investigation of Catalase Test}

Figure 2 showed the oral isolates did not give gas bubbles, therefore they were catalase negative.

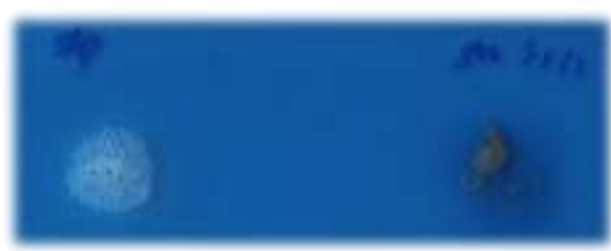

Staphylococcus

Streptococcus $\mathrm{S} 3 / 1$

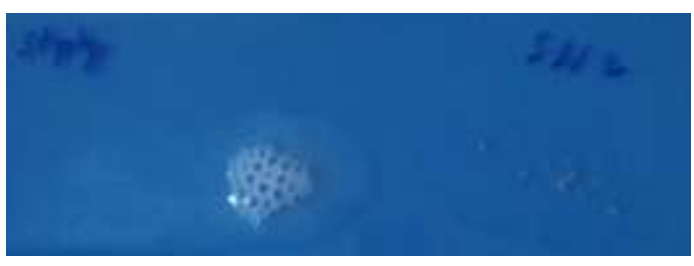

Staphylococcus
Streptococcus $\mathrm{S} 3 / 2$

Figure2. Catalase test of Oral Streptococcus Compare with Staphylococcus species 
International Journal of Advances in Scientific Research and Engineering (ijasre), Vol 6 (3), March -2020

\subsection{Identification of Isolated Oral Streptococcus Bacteria}

In this research, Strep Mannitol Agar with Bacitracin (SMAB) was used for identifying on unknown Streptococcus species. After 24 hours incubation, the media with isolated oral bacteria changed the $\mathrm{pH}$ of media, because of sugar fermentation. This changed from purple to yellow on selective agar.

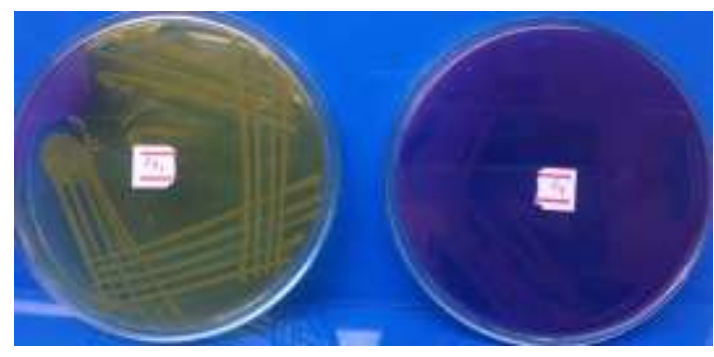

$\mathrm{S} 3 / 1$

Control

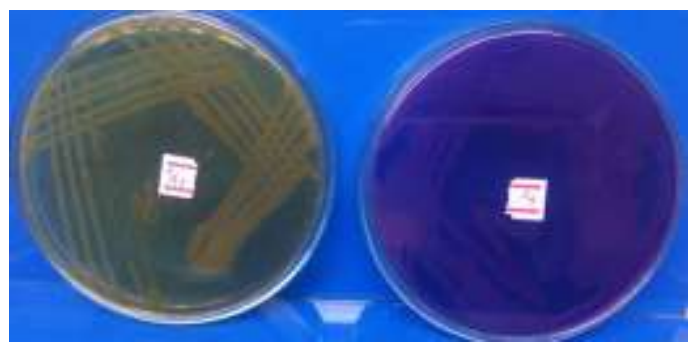

$\mathrm{S} 3 / 2$

Control

Figure3. Isolated Streptococcus species on Strep Mannitol Bacitracin Agar

\subsection{Inhibitory Activity against Isolated Oral Streptococcus species}

Four selected isolates were examined to investigate their antibacterial activity by agar well diffusion method. Inhibition effects of LAB culture broth against oral Streptococcus had been presented in figure 4 . At 24 hour incubation results showed that, the highest inhibitory activity isolated PP broth was $13 \mathrm{~mm}$ against oral Streptococcus $\mathrm{S} 3 / 1$ and S3/2. $\mathrm{S}_{1}$ broth was found against Streptococcus S3/1 (10 mm) and S3/2 (11 mm). Broth of isolated strain NP was showed against Streptococcus S3/1 and S3/2 (10 $\mathrm{mm})$. SC broth did not showed inhibitory activity to oral bacteria. According to these results, Lactobacillus species were shown to be able to produce organic acid and bacteriocins [13].
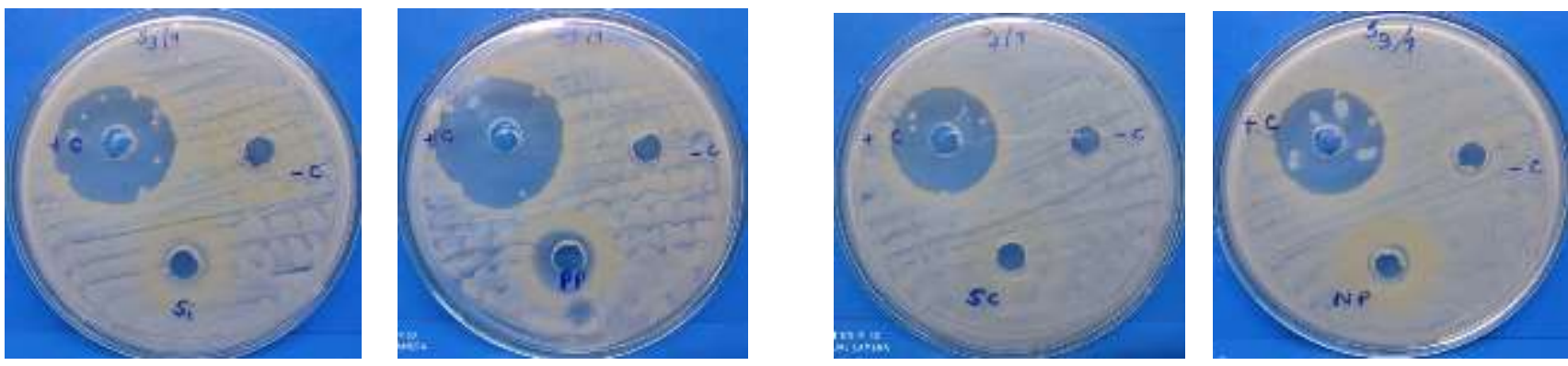

Figure4. Antibacterial Activity of Four LAB against Oral Streptococcus S3/1
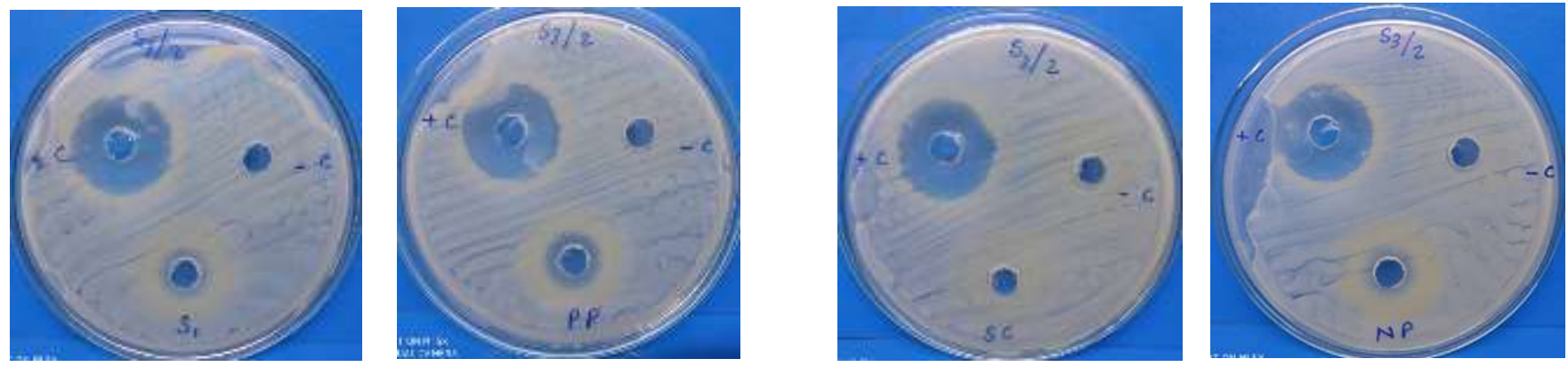

Figure5. Antibacterial Activity of Four LAB against Oral Streptococcus S3/2

\section{CONCLUSION}

Four strains were selected as acid producing bacteria and then they were identified as Lactobacillus plantarum, two strains of Leuconostoc mesenteroides and Burkholderia cenocepacia by 16S rRNA analysis. According to biochemical tests, isolated two oral bacteria were Streptococcus sp.which was confirmed by Strep Mannitol Agar. $\mathrm{S}_{1}$ and PP had antibacterial activity against oral bacteria (Streptococcus sp.). Therefore, these bacterial strains were suitable for industrial uses. 
International Journal of Advances in Scientific Research and Engineering (ijasre), Vol 6 (3), March -2020

\section{ACKNOWLEDGMENT}

Thanks to all teachers, Department of Biotechnology, Mandalay Technological University for their guidance, support and encouragement.

\section{REFERENCES}

1. Noordiana N.; A. B. Fatimah and A. S. Mun (2013). Antibacterial agents produced by lactic acid bacteria isolated from Threadfin Salmon and Grass Shrimp, International Food Research Journal 20 (1): 117.

2. FAO/WHO. Guidelines for the Evaluation of Probiotics in Food. Report of a Joint FAO/WHO, Working Group on Drafting Guidelines for the Evaluation of Probiotics in Food. Ontario, Canada, 2002

3. Stamatova I, Meurman JH. Probiotics: health benefits in the mouth. Am J Dent. 2009; 22:329-38.

4. Compare D, Rocco A, Coccoli P, et al. Lactobacillus casei DG and its probiotic reduce the inflammatory mucosal response: an ex-vivo organ culture model of post-infectious irritable bowel syndrome. BMC Gastroenterol. 2017; 17: 1-8.

5. Vuotto C, Longo F, Donelli G. Probiotics to counteract biofilm-associated infections: promising and conflicting data. Int J Oral Sci. 2014; 6: 189-94.

6. Marsh P, Martin MV (1999) Oral microbiology, 4th edn. Wright, Oxford.

7. Lenoir-Wijnkoop I, Sanders ME, Cabana MD, Caglar E, Corthier G, Rayes N, Sherman PM, Timmerman HM, Vaneechoutte M, Van Loo J, Wolvers DA (2007) Probiotic and prebiotic influence beyond the intestinal tract. Nutr Rev 65:469-489.

8. Meurman JH, Ten Cate JM (1996) Pathogenesis and modifying factors of dental erosion. Eur J Oral Sci 104:199-206.

9. Xie H, Lin X,Wang BY,Wu J, Lamont RJ (2007) Identification of a signalling molecule involved in bacterial intergeneric communication. Microbiology 153:3228-3234.

10. Paster BJ, Olsen I, Aas JA, Dewhirst FE (2006) The breadth of bacterial diversity in the human periodontal pocket and other oral sites. Periodontol 2000 42:80-87.

11. Meurman JH, Stamatova I (2007) Probiotics: contributions to oral health. Oral Dis 13:443-451.

12. Cadirci BH, Citak S. A comparison of two methods used for measuring antagonistic activity of lactic acid bacteria. Pak J Nutr. 2005; 4: 237-41.

13. Donelli G. Activity of probiotics on biofilm growing pathogens of the oral cavity. Microb Ecol Health Dis. 2013; $24: 6$ 